\title{
Determinants of Exocrine Pancreatic Function as Measured by Fecal Elastase-1 Concentrations (FEC) in Patients with DiABETES MELLITUS
}

\author{
N. Ewald, A. Raspe, C. Kaufmann, R. G. Bretzel, H. U. Kloer, P. D. Hardt \\ Third Medical Department and Policlinic, University Hospital Giessen and Marburg, Giessen Site, Germany
}

\begin{abstract}
Objective: Recently it has been shown that there is not only endocrine insufficiency in diabetic patients, but a frequent co-morbidity of both, the endocrine and exocrine pancreas. The present study was performed to further analyse the determinants of exocrine pancreatic function in patients with diabetes mellitus.

Methods: The records of 1992 patients with diabetes mellitus who had been treated in our hospital during a 2-year period were re-evaluated. Defined parameters were documented in standardized data sheets. Records were further checked for the results of imaging procedures of the pancreas. In 307 patients FEC had been performed and documented. Only these patients were included in further evaluation.

Results: FEC was inversely correlated with diabetes duration and HbA1c-levels but not with age. C-peptide levels correlated positively with FEC. BMI and FEC were also significantly correlated. There was no correlation between diabetes therapy and exocrine pancreatic function as there was no correlation with any concomitant medication. The presence of diabetes-associated antibodies was not related to FEC. According to the documented data 38 were classified as type-1 diabetes (12.4\%), 167 as type-2 (54.4\%), and 88 patients met the diagnostic criteria of type-3 $(28.7 \%)$. Fourteen patients could not be classified because of lacking information $(4.6 \%)$.

Conclusions: Exocrine insufficiency might be explained as a complication of diabetes mellitus. However, it is more likely that type- 3 diabetes is much more frequent than previously believed. Consequently the evaluation of exocrine function and morphology should be included into the clinical workup of any diabetic patient at least at the time of manifestation.

Key words: diabetes mellitus, exocrine pancreatic function, fecal elastase, type 3 diabetes
\end{abstract}

\section{INTRODUCTION}

As a consequence of the close anatomical and physiological proximity of exocrine and endocrine pancreas, exocrine pancreatic morphology and function have been studied in patients with diabetes mellitus in numerous studies. Dating back to 1943 [1] and during the following decades direct function tests (e.g. secretin-test and modifications) have been used for this purpose and a prevalence of $43-80 \%$ of exocrine insufficiency has been reported in patients with insulin dependent diabetes mellitus (IDDM) [2-6]. Since the use of direct function tests is rather invasive and inconvenient these studies have been limited to rather small numbers of patients.

In 1992, the measurement of fecal elastase-1 concentrations (FEC) by means of an ELISA based on monoclonal specific antibodies was suggested as a new indirect test of exocrine pancreatic function [7] and became commercially available (ScheBo Biotech, Giessen, Germany). This test was validated in comparison with direct function tests and results of imaging procedures. It proofed to be sensitive in moderate and severe pancreatic insufficiency and it correlated with pancreatic duct changes in ERCP images $[8,9]$. Despite some critical comments $[10,11]$ it has become a standard test for indirect measurement of exocrine function during the last years for its clinical usefulness $[12,13]$. Utilising this non-invasive test, it became possible to screen larger patient groups and several studies used it to investigate larger populations of both, patients with type- 1 and type- 2 diabetes mellitus. These studies included up to 1000 patients and reported a high prevalence in both, type-1 (50-60\%) [14, 15, $16]$ and type- 2 diabetes $(35-40 \%)[14,16,17]$. Summarizing the results of direct and indirect tests there can be no doubt that exocrine pancreatic insufficiency is very frequent in patients with diabetes mellitus. Additionally, there have been a number of reports on morphologic changes of the exocrine pancreas (atrophy, fibrosis, chronic pancreatitis) including histology, ultrasound, CT and ERCP [18-23].

Therefore it has to be noticed that there is not only endocrine insufficiency in diabetic patients, but a frequent co-morbidity of both, exocrine and endocrine pancreas.

A number of hypothesis have been raised to explain these findings: exocrine pathology might be a result of local insulin deficiency or neuropathic changes in diabetes mellitus. The prevalence of type-3 diabetes might be higher than believed previously or autoimmune diseases could involve both parts of the gland. While the relevance of these hypotheses is still under debate, some recent studies observed that there is a correlation between FEC and residual beta cell function, quality of diabetes control [24] and diabetes duration [16] suggesting exocrine dysfunction to be a complication of diabetes mellitus. Since the arguments have not been convincing so far, we decided to re-evaluate the records of patients having been hospitalized 
with the diagnosis of diabetes mellitus in our institution during a 2 year period (01.01.2003-31.12.2004) concerning diabetes classification, diabetes associated parameters and exocrine pancreatic function.

\section{Methods And Statistics}

The records of 1992 patients with diabetes mellitus who had been hospitalized and treated in our institution during a 2 year period (01.01.2003-31.12.2004) were re-evaluated. Defined parameters were documented in standardized data sheets.

The parameters comprised data of patients' history (diabetes duration, diabetes therapy, complications, concomitant therapy and other diseases e.g. celiac disease) and clinical symptoms related to diabetes and the GI-tract. Laboratory markers included diabetes associated antibodies, other immunological markers, HbA1c, C-peptide levels, fecal elastase-1 concentrations (FEC). Records were further checked for the results of imaging procedures of the pancreas (ERCP, MRT, Ultrasound, CT).

In 307 patients FEC had been performed and documented. Only these patients were included in further evaluation.

The diabetes type was reclassified according to the classification of the American Diabetes Association [25] on the basis of the parameters available. Type-1 diabetes was diagnosed, if diabetes associated antibodies were present and patients were insulin dependent at diagnosis. Patients with high C-peptide levels and $\mathrm{BMI}>25 \mathrm{~kg} / \mathrm{m}^{2}$ without antibodies were classified as type-2. Type-3 diabetes was diagnosed in patients when exocrine pancreatic insufficiency and pathologic imaging results were available in the absence of diabetes associated antibodies.

For statistical analysis SPSS V11.5 was used. Data analysis included mean, median and standard deviations. Kolmogorov-Smirnov-test was used to test Gaussian distribution. Pearson-test or Spearman-Rhotest was used to investigate correlations between diverse parameters.

\section{RESULTS}

In 307 patients FEC were available. These were included to further evaluation. Of these, 138 were female $(45 \%)$ and 169 male $(55 \%)$. According to the data documented in the files, 38 were classified as type-1 diabetes (12.4\%), 167 as type-2 diabetes (54.4\%), and 88 patients met the diagnostic criteria of type- 3 diabetes $(28.7 \%)$. Fourteen patients could not definitely be classified because of lacking information (4.6\%).

The mean age was younger in type- 1 patients and similar in types 2 and 3 (Table 1 ).

Diabetes duration, HbA1c- and C-peptide levels in the different types of diabetes are shown in Table 1. Patients classified as type- 2 diabetes had the shortest duration of the disease, higher C-peptide levels and better glycemic control than type-3 and type-1 patients. FEC are shown in Table 2, the prevalence of exocrine insufficiency in different diabetes types is shown in Figure 1. FEC did slightly decrease with age, but this was not statistically significant (Fig. 2). Obvi-
Table 1. Patients 'characteristics concerning age, diabetes duration, $\mathrm{HbA} 1 \mathrm{c}$ and $\mathrm{C}$-peptide-levels.

\begin{tabular}{|c|c|c|c|c|}
\hline \multirow{2}{*}{$\begin{array}{l}\text { Diabetes- } \\
\text { type }\end{array}$} & \multirow[b]{2}{*}{ Mean } & \multicolumn{2}{|c|}{ Age (years) } & \multirow{2}{*}{ Maximum } \\
\hline & & Median & Minimum & \\
\hline Type-1 & 41.8 & 42 & 14 & 75 \\
\hline Type-2 & 59.8 & 62 & 32 & 84 \\
\hline \multirow[t]{2}{*}{ Type-3 } & 60.5 & 62 & 21 & 83 \\
\hline & \multicolumn{4}{|c|}{ Diabetes Duration (years) } \\
\hline Type-1 & 11.8 & 9 & 0.0 & 52 \\
\hline Type-2 & 7.9 & 5 & 0.0 & 36 \\
\hline \multirow[t]{2}{*}{ Type-3 } & 11.5 & 9 & 0.5 & 37 \\
\hline & \multicolumn{4}{|c|}{ HbA1c (\%) } \\
\hline Type-1 & 8.3 & 8 & 5 & 14.5 \\
\hline Type-2 & 7.4 & 6.9 & 4.2 & 14.5 \\
\hline \multirow[t]{2}{*}{ Type-3 } & 7.9 & 7.8 & 4.8 & 13.4 \\
\hline & \multicolumn{4}{|c|}{ C-Peptide ( $\mu g / 1)$} \\
\hline Type-1 & 1.1 & 1.1 & 0.0 & 4.1 \\
\hline Type-2 & 3.2 & 2.7 & 0.5 & 7.6 \\
\hline Type-3 & 2.1 & 1.9 & 0.5 & 5.9 \\
\hline
\end{tabular}

Table 2. Fecal Elastase-1 concentrations (FEC) in 307 patients.

\begin{tabular}{lrrccc}
\hline $\begin{array}{l}\text { Diabetes- } \\
\text { type }\end{array}$ & n & Mean & $\begin{array}{c}\text { FEC }(\boldsymbol{\mu g} / \mathbf{g}) \\
\text { Median }\end{array}$ & Minimum & Maximum \\
\hline Type-1 & 38 & 326.4 & 383.5 & 0 & 685 \\
Type-2 & 167 & 396.5 & 395 & 0 & 826 \\
$\begin{array}{l}\text { Type-3 } \\
\text { Not }\end{array}$ & 14 & 94.4 & 94 & 0 & 199 \\
$\begin{array}{l}\text { classified } \\
\text { Sum }\end{array}$ & 307 & 290.5 & 143 & 37 & 761 \\
\hline
\end{tabular}

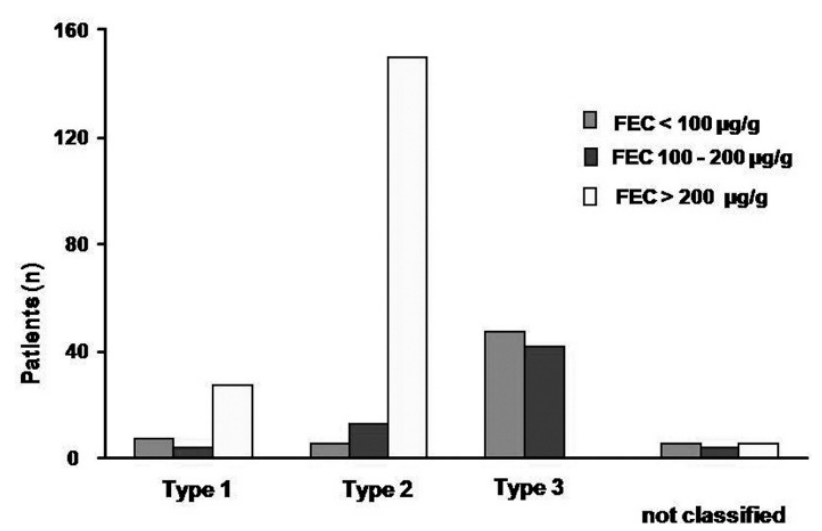

Fig. 1. Number of patients with exocrine insufficiency as measured by fecal elastase- 1 concentrations (FEC)

ously pancreatic exocrine insufficiency (PEI) was more frequent in type- 3 diabetes because this made part of the definition. However, there were also several cases of PEI in the other diabetes types. FEC was inversely correlated with diabetes duration ( $p=0.004$, Fig. 3) and HbA1c-levels ( $\mathrm{p}=0.031$, Fig. 4). C-peptide levels correlated positively with FEC ( $<<0.001$, Fig. 5). BMI and FEC were also significantly correlated $(\mathrm{p}=0.042$, Fig. 6). There was no correlation between diabetes 

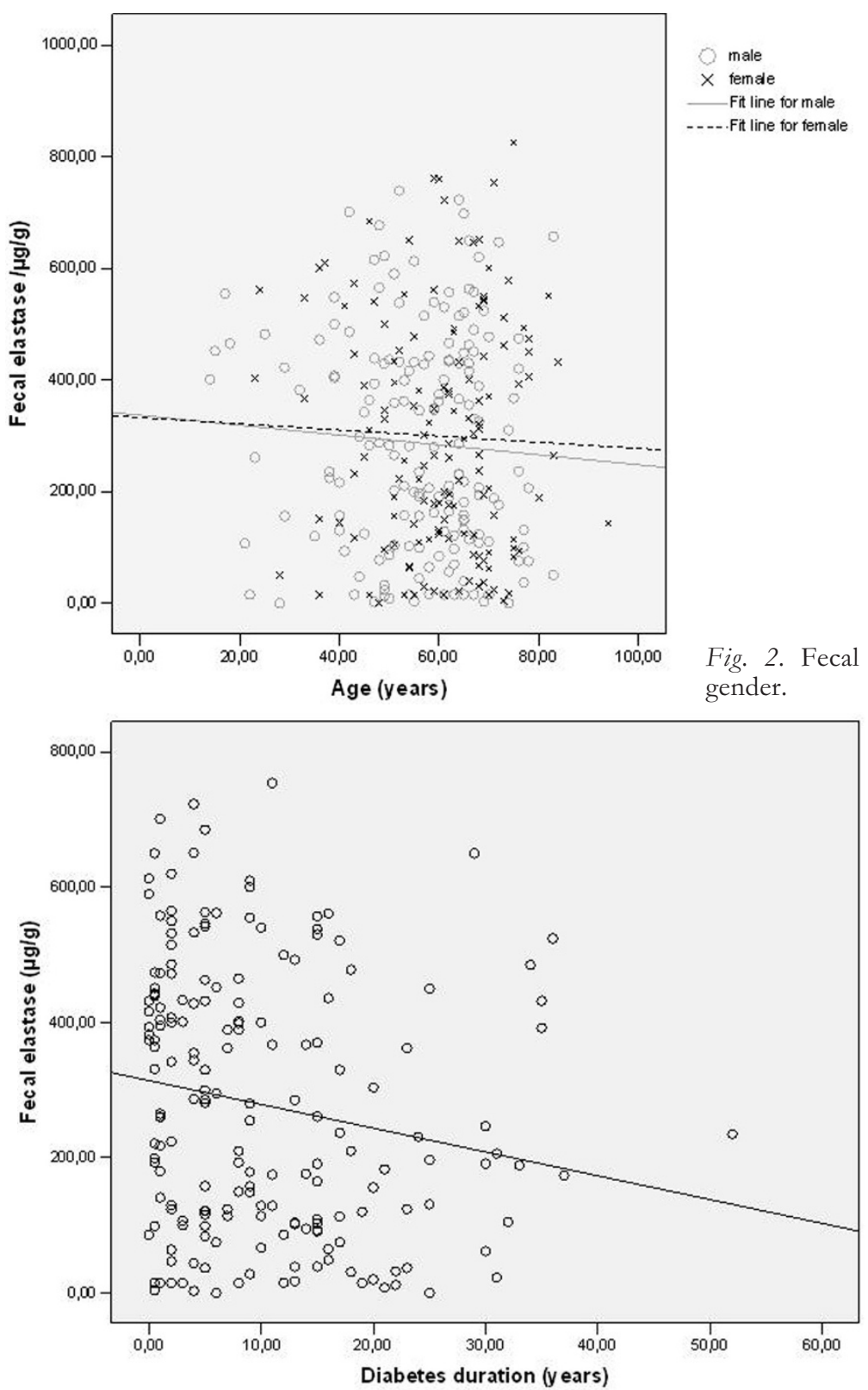

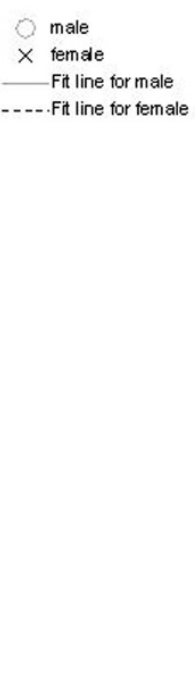

Fig. 2. Fecal elastase-1 concentrations depending on age and gender.

Fig. 3. Fecal elastase-1- concentrations (FEC) and diabetes duration. therapy and exocrine pancreatic function as there was no correlation with any concomitant medication. The presence of diabetes-associated antibodies was not related with FEC. Other immunological markers (e.g. thyroid or celiac disease) had been evaluated only in a minority of patients, therefore statistical analysis appeared not to be reasonable.

\section{Discussion}

Summarizing the results of functional and morphological studies of the exocrine pancreas in patients with diabetes mellitus, it has to be noticed that there is not only exocrine insufficiency in diabetic patients, but a frequent co-morbidity of both, exocrine and endocrine pancreas [1-24].

This could be explained in part by the assumption that pancreatic diabetes mellitus (type-3) must be more frequent than previously believed $[4,14,16]$. In the general opinion type- 3 diabetes has been described to account for about $1 \%$ of diabetics [26]. These estima- tions dating back to the 1960s and 1980s have probably been biased because the evaluation of the exocrine pancreas had been limited due to highly invasive procedures (direct function tests, ERP). However, since indirect function tests, ultrasound, CT and MRT made it easier to asses function and morphology of the exocrine portion of the gland, it has been used more frequently and a higher prevalence of type- 3 diabetes appears to be reasonable. Reclassifying the patients of the present study according to the suggestions of the American Diabetes Association [25] on the basis of the data documented in the patients charts, we found that in our population type-3 diabetes was even more common than type-1 patients. Of course there must be a certain bias, because exocrine pancreatic function had only been evaluated in 307 out of 1992 patients and it was not part of the standard evaluation program for diabetic patients. Therefore it is likely that FEC testing has been done rather in patients with a suspicion of exocrine disease than in others. However, even if all patients not being tested for exocrine func- 

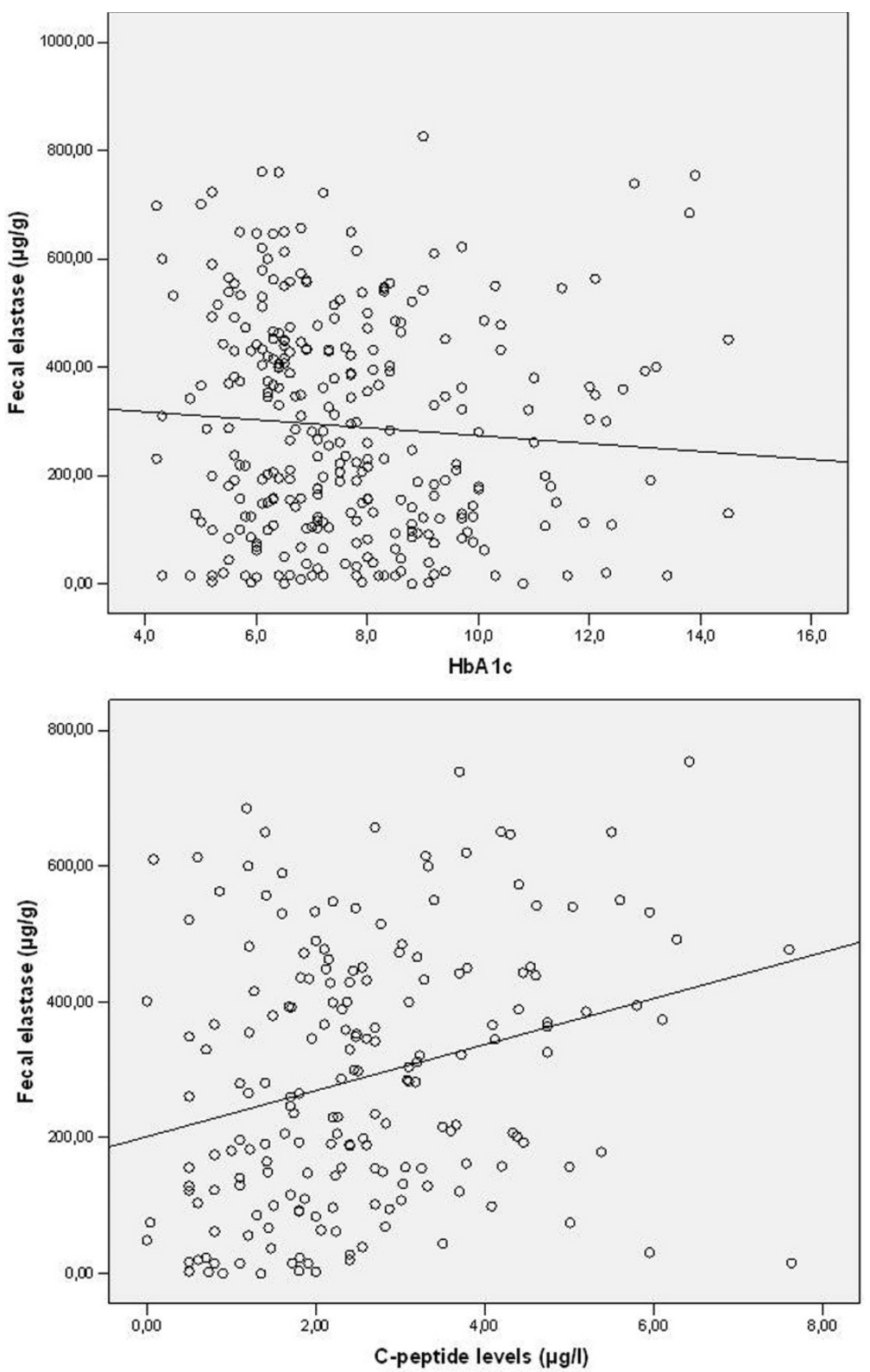

Fig. 4. Fecal elastase-1- concentrations (FEC) and $\mathrm{HbA1c}$.

Fig. 5. Fecal elastase-1- concentrations (FEC) and C-peptide levels. tion had normal values, on the bases of 38 being classified as type- 3 by morphological and functional findings the percentage of pancreatic diabetes within 1992 patients would still be $4.2 \%$. This is a remarkable finding, since the treatment of type- 3 diabetes bears some peculiarities different from other diabetes types.

It has also been claimed that local insulin deficiency and a loss of the trophic insulin effects on surrounding beta cells could explain the finding of pancreas atrophy at least in patients with type-1 diabetes. While most of the older studies did not describe correlations between exocrine pancreatic function and residual beta cell activity or diabetes duration there have been reports on this more recently $[16,24]$. In the present study we also observed declining concentrations of fecal elastase-1 with diabetes duration but not with age. Furthermore, C-peptide levels were correlated positively. Thus exocrine insufficiency might also be explained as a complication of diabetes mellitus.

To learn more about the clinical relevance of type-3 diabetes mellitus and the pancreatic complications of diabetes mellitus future studies should prospectively investigate exocrine pancreatic function in patients diagnosed with diabetes mellitus. At present is seems to be reasonable for the clinical workup to evaluate exocrine function and morphology in any diabetic patient at least at the time of diabetes manifestation.

\section{REFERENCES}

1. Pollard HM, Miller L, Brewer WA. The external secretion of the pancreas and diabetes mellitus. American Journal of Digestive Diseases 1943 10: 20-23.

2. Dreilling DA. Studies in pancreatic function. IV. The use of the secretin test in the diagnosis of tumors in and about the pancreas. Gastroenterology 1951 18: 184-196.

3. Chey WY, Shay H, Shuman CR. External pancreatic secretion in diabetes mellitus. Ann Intern Med 1963 59: 812-821.

4. Vacca JB, Henke WJ, Knight WA. The exocrine pancreas in diabetes mellitus. Ann Intern Med 1964 61: 242-247.

5. Frier BM, Saunders JHB, Wormsley KG Bouchier IAD. Exocrine pancreatic function in juvenile-onset diabetes mellitus. Gut 1976 17: 685-691.

6. Lankisch PG, Manthey G, Otto J, Talaulicar M, Willms B, Creutzfeldt W. Exocrine pancreatic function in insulin-dependent diabetes mellitus. Digestion 1982 25:210-216. 


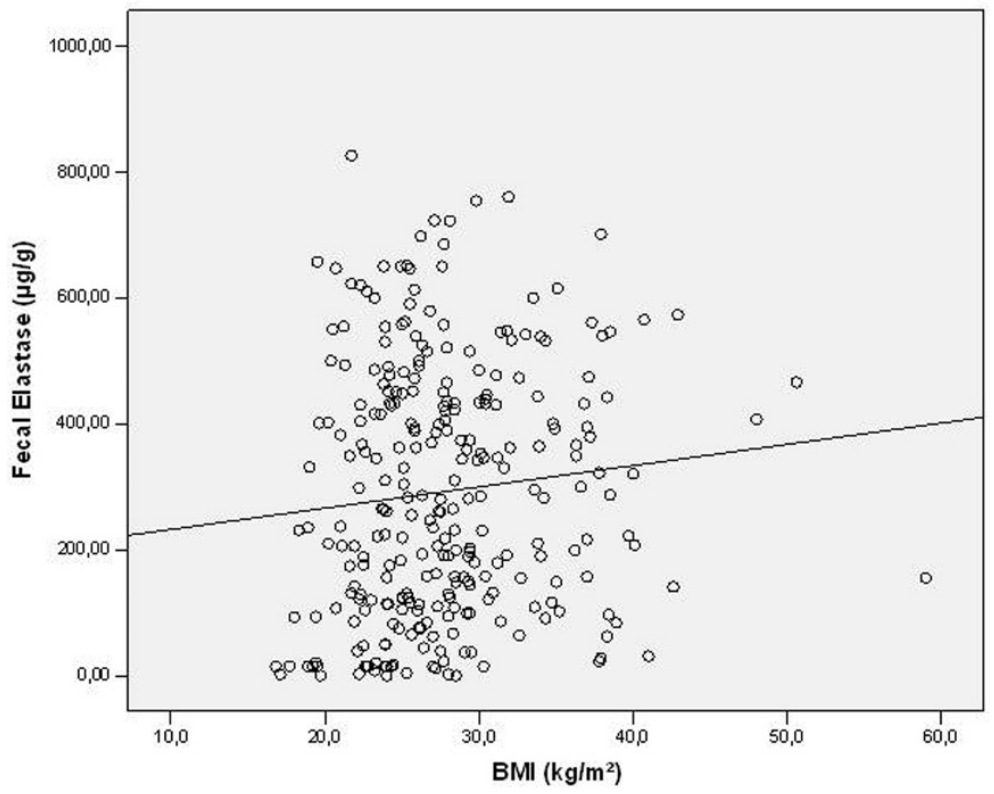

Fig. 6. Fecal elastase-1- concentrations (FEC) and Body Mass Index (BMI).
7. Scheefers-Borchel U, Scheefers H, Arnold R, Fischer P, Sziegoleit A. Pankreatische Elasatase 1: Parameter für die chronische und akute Pankreatitis. Lab Med 1992 16: 427432.

8. Löser C, Möllgaard A, Fölsch UR. Faecal elastase 1: a novel, highly sensitive, and specific tubeless pancreatic function test. Gut 1996 39: 580-586.

9. Hardt PD, Marzeion AM, Schnell-Kretschmer H, Wusten O, Nalop J, Zekorn T, et al. Fecal elastase 1 measurement compared with endoscopic retrograde cholangiopancreatography for the diagnosis of chronic pancreatitis. Pancreas 2002 25:e6-9.

10. Lankisch PG, Schmidt I, König H, Lehnick D, Knollmann R, Lohr M, et al. Faecal elastase 1: not helpful in diagnosing chronic pancreatitis associated with mild to moderate exocrine pancreatic insufficiancy. Gut 1998 42: 551-554.

11. Siegmund E, Lohr JM, Schuff-Werner P. The diagnostic validity of non-invasive pancreatic function tests--a metaanalysis. Z Gastroenterol 2004 42: 1117-1128.

12. Molinari I, Souare K, Lamireau T, Fayon M, Lemieux C, Cassaigne A, et al. Fecal chymotrypsin and elastase-1 determination on one single stool collected at random: diagnostic value for exocrine pancreatic status. Clin Biochem 2004 37:758-763.

13. Elphick DA, Kapur K. Comparing the urinary pancreolauryl ratio and faecal elastase- 1 as indicators of pancreatic insufficiency in clinical practice. Pancreatology 2005 5:196200.

14. Hardt PD, Krauss A, Bretz L, Porsch-Oezcueruemez M, Schnell-Kretschmer H, Maeser E, et al. Pancreatic exocrine function in patients with type- 1 and type- 2 diabetes mellitus. Acta Diabetologia 2000 37: 105-110.

15. Icks A, Haastert B, Giani G, Rathmann W. Low fecal elastase 1 in type 1 diabetes mellitus. Z Gastroenterol 2001 39: 823-830.

16. Hardt PD, Hauenschild A, Nalop J, Marzeion AM, Jaeger $\mathrm{C}$, Teichmann J, et al. High prevalence of exocrine pancreatic insufficiency in diabetes mellitus. A multicenter study screening fecal elastase 1 concentrations in 1,021 diabetic patients. Pancreatology 2003 3: 395-402.

17. Rathmann W, Haastert B, Icks A, Giani G, Hennings S, Mitchell J, et al. Low fecal elastase 1 concentrations in Type 2 diabetes. Scand J Gastroenterol 2001 36: 1056-1061.

18. Loehr M, Kloeppel G. Residual insulin positivity and pancreatic atrophy in relation to duration of chronic type 1 (insulin dependent) diabetes mellitus and microangiopathy. Diabetologia 1987 30: 757-762.
19. Gilbeau J, Poncelet V, Libon E Derue G, Heller FR. The density, contour and thickness of the pancreas in diabetics. Am J Roentgenol 1992 159: 527-531.

20. Lazarus SS, Volk BW. Pancreas in maturity-onset diabetes. Arch Path (Chicago) 1961 71: 44-48.

21. Gepts W. Pathology of the pancreas in juvenile diabetes. Diabetes 1965 14: 619-633.

22. Nakanishi K, Kobayashi T, Miyashita H, Okubo M, Sugimoto T, Murase T, et al. Exocrine pancreatic ductograms in insulin-dependent diabetes mellitus. Am J Gastroenterol 1994 89: 762-766.

23. Hardt PD, Bretz L, Krauss A, Schnell-Kretschmer H, Wüsten $\mathrm{O}$, Nalop J, et al. Pathological pancreatic exocrine function and duct morphology in patients with cholelithiasis. Dig Dis Sci 2001 46: 536-539.

24. Cavalot F, Bonomo K, Perna P, Bacillo E, Salacone P, Gallo M, Mattiello L, et al. Pancreatic elastase-1 in stools, a marker of exocrine pancreas function, correlates with both residual beta-cell secretion and metabolic control in type 1 diabetic subjects. Diabetes Care 2004 27: 2052-2054.

25. The Expert Committee on the diagnosis and classification of Diabetes mellitus. Report of the Expert Committee on the diagnosis and classification of diabetes mellitus. Diabetes Care 1998; 21, Suppl 1: 5-19.

26. Alberti KGMM. Diabetes secondary to pancreatopathy: an example of brittle diabetes. In: Tiengo A, Alberti KGMM, DelPrato S, Vranic M (eds). Diabetes secondary to Pancreatopathy. International Congress Series 762, Amsterdam: Excerpta Medica, Amsterdam 1988, 7-20.

Received: January 15, 2009 / Accepted: January 26, 2009

Address for correspondence:

Dr. Nils Ewald

University Hospital of Giessen and Marburg

Giessen Site

Third Medical Department and Policlinic

Rodthohl 6

35392 Giessen

Germany

Phone: +49-641-9942751

Fax: +49-641-9942757

E-mail: nils.ewald@innere.med.uni-giessen.de 